\title{
NOTES AND CORRESPONDENCE
}

\section{HYDROGENATION OF OIL}

[The following opinion was rendered Oct. 3 , I917, by Judge Augustus N. Hand, of the U. S. District Court (Southern District of N. Y.) on the Burchenal Patent No. I, I35,35 I in case of Proctor and Gamble Co. (Complainant) vs. Berlin Mills Co. (Defendant). Kerr, Page, Cooper and Hayward were Solicitors for the Complainant with Alfred N. Allen, Livingston Gifford and Thomas B. Kerr as Counsel. For the Defendant, John C. Pennie was Solicitor, with Marcus B. May and Mr. Pennie as Counsel. 1

This suit is for infringement of patent No. I, I3,35I, granted to the Complainant as assignee of John J. Burchenal, on April 13. I915. The application for the patent was filed November Io, I9 I0. The specification states that the invention is for a food product consisting of a vegetable oil, preferably cottonseed oil, partially hydrogenized and hardened to a homogeneous white or yellowish semi-solid clearly simulating lard.

Claims $\mathrm{I}$ and 2 alone are in issue and read as follows:

1-A honogeneous lard-like food product consisting of an incompletely hydrogenized vegetable oil.

2-A homogeneous lard-like tood product consisting of incompletely bydrogenized cottonseed oil.

The special object of the invention is, according to the specification:

* * * to provide a new fbod product for a shortening in cooking in which the liability to become rancid is minimized and in which the components of such vegetable oils which are inferior and detrimental to use as such a food product have been to a large extent converted into a higher and more wholesome form. All such vegetable oils contain, glycerids of unsaturated fatty acids and among these notable quantities of fatty glycerids of lower saturation than olein. It is the presence of these glycerids of lower saturation that seriously affects the rancidity of the material. Oxidation is largely the cause of rancidity, which oxidation weakens the fat at the point of absorption at the double bonds, and these glycerids of lesser saturation readily absorb oxygen from the air at ordinary tempera. tures while the more highly saturated glycerias, as clein, only absorb oxygen at elevated temperatures. It is evident therefore, that oils or fats containing notable quantities of glycerids of linolic acid or of lesser saturation are distinctly inferior as an edible product to those containing a minimum of these glycerids with a larger per cent of olein. On the other hand, while it is important to get rid of the readily oxidizable glycerids of lower saturation, it is also important not to supply too large a per cent of fully saturated glycerids.

* * * In manufacturing this product, cottonseed or other vegetable oil is caused to chemically absorb a limited amount of hydrogen by reacting on the oil with hydrogen in the presence of a catalytic agent and at an elevated temperature. The oil is preferably agitated in a closed vessel in the presence of an atmosphere of compressed hydrogen, a catalyzer of finely-divided nickel carried by kieselguhr being maintained in suspension in the oil and its temperature being raised to about $155^{\circ} \mathrm{C}$.

According to the present invention, the amount of hydrogen absorbed is carefully regulated and limited. In practice, the operation is stopped when the oil has been converted into a product which cools to a white or yellowish semi-solid more closely resembling lard than do the commercial mixtures of cottonseed oil and animal oleo-stearin while in many respects the product is superior to the best leaf lard as a shortening. It is not so liable to become rancid and the product can be heated to a considerably higher temperature than lard without smoking or burning. The high temperature to which my product can be raised without smoking or burning makes the product ideal for trying inasmuch as a crust forms almost instantly on the food fried, which prevents any absorption of the shortening. A lard-like product thus prepared from cottonseed oil has a saponification value of about 19.5 and an ioain value ranging from about 55 to about 80 . The product having an iodin value of 55 has a titer of about $42^{\circ}$ and a melting point of about $40^{\circ} \mathrm{C}$, that having an iodin value of 80 has a titer of about $35^{\circ}$ and a melting point of about $33^{\circ} \mathrm{C}$. While but partially hydrogenized, containing from about 1.5 per cent to 2.5 per cent of additional hydrogen more than in the non-hyorrogenized material, it shows no free cottonseed oil when subjected to the Halphen test, thereby differing from all commercial lard substitutes containing this oil. It contains from twenty to twenty-five per cent of fully saturated glycerids, from five to ten per cent linolin, and from sixty-five to seventy-five per cent olein; and an average of a number of samples gives twenty-three per cent of saturated fats, seven and five-tenths per cent linolin and sixty-nine and five-tenths per cent olein, while the cottonseed oil before treatment contained seventeen per cent saturated fats, thirty-seven per cent linolin and forty-six per cent olein. It will thus be seen that I have produced an ideal food product which is high in olein, low in linolin and lesser saturated fats and with only enough stearin to make the product congeal at ordinary temperatures.

The complainant urges that Burchenal first taught the art that a partially hydrogenated vegetable oil, preferably cottonseed oil, was edible and was a useful lard substitute. It contends that prior to Burchenal's conception it was not known that hydrogenated cottonseed oil was edible and that the only processes then in use aimed at complete saturation and produced a hard non-edible product. Before discussing the prior art, I would say in general that Normann, whose patent will later be referred to, had already disclosed a method of hydrogenating oils, and had set forth in his specification that the process was progressive and involved "no secondary reaction." The method of adding cottonseed oil to beef stearin for use as a lard compound was well known and much used, as it still is. The hydrogenation of cottonseed oil resulted in a reduction of the fluid and substitution of the solid fats. Normann's patent, as well as various experiments of scientists, indicated that the addition of hydrogen to cottonseed oil would result in the reduction or elimination of the fluid and substitution of solid or partially solid fats. No one has shown that the product resulting from such hydrogenation was ever non-edible or unsanitary in any respect.

The British patent No. 0,83 ( 1887 ), to Joseph Sears, was for a lard substitute composed of refined unbleached cottonseed oil and a fat adapted to give a stiffiness to the compound corresponding substantially to that of refined lard. The specification provided that the temperature should be raised sufficiently to melt the fat or stearin, the heated ingredients mixed and then chilled rapidly so as to prevent crystallization and separation. This general process was well known in the art before the date claimed for the invention of Burchenal and indeed is referred to in the patent in suit. A very large market for such lard-like compounds exists at the present time and has existed many years past.

The British patent No. I5I5 of I903, to Normann, discloses a process for the reduction of glycerines resembling that of the patent to Burchenal. Normann's patent says that:

The prope:ty of finely civided platinum to exercise a catalytic action with hydrogen *** is already known. *** Recently Sabatie and Senderens of Paris have discovered that other finely divided metals will also exercise a catalytic effect on hydrogen; viz., iron, cobalt, copper and especially nickel.

By causing acetylene, ethylene or benzene vapor in mixture with hydro. gen gas to pass over one of the said metals (which had just been reduced in a current of hyarogen) the said investigators obtained from the unsaturated hydrocarbons, saturated hydrocarbons, partly with simultatseous condensation.

I have found that by this catalytic method it is easy to convert un. saturated fatty acids into saturated acids.

This may be effected by causing fatty acid vapors, together with hydiogen, to pass over the catalytic metal, which is preferably distributed over a suitable support such as pumice stone. It is sufficient. however, to expose the fat or the fatty acid in a liquid condition to the action of hydrogen and the cataly tic substance.

For instance, if fine nickel powder. obtained by reduction in a hyarogen current, is added to chemically pure oleic acid, the latter heated over an oil bath and a strong current of hydrogen is caused to pass through it for a considerable time, the oleic acid may be completely converted into steáric acid,

The quantity of the nickel thus added and the temperature are immaterial and will only affect the duration of the process. Apart from the formation of smail quantities of nickel soap. which may be easily decomposed by dilute mineral acids, the reaction passes off without any secondary reaction. The same nickel may be used repeatedly. Instead of pure oleic acid, commercial fatty acids may be treated in the same manner. The fatty acid of tallow which melts between 44 and $48^{\circ} \mathrm{C}$. has an iodine number 35,1 and a yellow color will after hydrogenation melt between 56.5 and $59^{\circ}$, while its iodine number is 98 and its color slightly lighter than before, and it will be very hard.

The same method is applicable not only to free fatty acids, but also to the glycerines occurring in nature, that is to say, the fats and oils. Olive oil will yield a hard tallow-like mass; linseed oil and fish oil will give similar results.

By the new method all kinds of unsaturated fatty acids and their giycerides may be easily hydrogenized.

The Normann patent clearly discloses that oils may be completely hydrogenized, that the process is progressive and that it 
involves "no secondary reaction," in other words, that cottonseed oil which starts edible remains so. The experiments and articles of Paul and Roth, which were alluded to at the trial, show that hydrogenization of oils including cottonseed oil was understood in the prior art.

Such being the state of the art, Edwin Cuno Kayser wrote Procter \& Gamble from England that he had a process of considerable value and would like to talk to them about it; thereafter he came to America, about November, I907, bringing samples of hydrogenized cottonseed oil. He showed these to Burchenal, the superintendent of Procter \& Gamble. As a result of his visit, he made an arrangement under a preliminary contract of January, igu8, to experiment upon the hydrogenized cottonseed oil as a substitute for lard. The first project was apparently to use hydrogenated cottonseed oil as a compound to be added to a percentage of beef stearin and cottonseed oil. Burchenal says he had done no work in connection with hydrogenizing cottonseed oil before he saw Kayser. He testified that:

'Mr. Kayser went out to our factory and made sketches as to the ap. paratus that would be necessary to carry on this work, and the apparatus was ordered at once; a little plant was installed for experimental purposes and I think it was ready to operate sometime in January or February, 1908" (Deposition of Burchenal, page 11).

The defendant succeeded in obtaining contemporaneous memoranda as to some of Kayser's experiments from the records of Procter \& Gamble. The first experiment was as follows:

\section{Fat Hardening Process by E. C. Kayser}

First experimental lot was completed January 17, 1908. Fat treated -Summer Yellow Cottonseed Oil. Used Nickel Sulfate and Kieselguhr as described. Experiment was conducted by Mr. Kayser alone. He claims to have used about I per cent Nickel Metal and 2 per cent Kieselguhr. M. p. of fat after $3 \mathrm{hrs}, 551 / 2^{\circ} \mathrm{C}$

M. p. of fat after $61 / 2 \mathrm{hrs} ., 60.3^{\circ} \mathrm{C}$.

Dr. Bender reports as follows:

Melting point of fat, $60.3^{\circ} \mathrm{C}$

Hydrocarbons, 0.33 per cent.

Iodine value of fat, 7.14 per cent.

The fat does not contain free fatty acids. This material is much superior to the samples, rom J. Crossfield \& Sons, which showed an iodine value of 52.26 and a melting point of $39.3^{\circ} \mathrm{C}$. (The laboratory sample melted at $49.9^{\circ} \mathrm{C}$.). Their samples contained 5.12 per cent free fatty acids and 2 per cent hydrocarbons.

Mr. Kayser reports as follows: "The melting point of fatty acid, prepared from first lot harcened cottonseed oil, is $62^{\circ} \mathrm{C}$. This is several points higher than I ever got before. Presumably the composition of your oil differs somewhat from that of the oil I handlea formerly."

Another experiment by Kayser of the date of March 5, 1908, was also obtained from the Procter \& Gamble records, in which the following melting points appeared:

$$
\begin{aligned}
& 5 \mathrm{hrs} \text { at ordinary pressure, } 42^{\circ} \mathrm{C} \text {. } \\
& 11 / 2 \mathrm{hrs} \text {, at } 60 \mathrm{lb} \text {. pressure, } 43^{\circ} \mathrm{C} \text {. }
\end{aligned}
$$

Von Phul testified that Kayser told him in I907 that he was getting up a patent for a food product and even Burchenal's own testimony shows that Kayser supposed that the product he was making was edible. If Kayser at first told him it was not edible, he did so when they were negotiating and he wished to keep his process in the dark until he had arranged his terms. That Kayser's statement that it was not edible was not taken seriously by either party is shown by the following testimony:

Q. 887. But you did not know as a matter of fact whether it would be edible or not? A. I did not. Mr. Kayser stated that it would not be, but that was his method of talking.

Both of these men were proceeding soon after Kayser's arrival in this country to develop hydrogenated cottonseed oil as a food product. Even if the thought first occurred to Burchenal I cannot see that he did anything to carry it out in practice. Kayser's patent No. I,OO4,035, application for which was filed March 20, 1908, disclosed the process which was employed to make the product covered by the patent in suit, and the specification for this Kayser patent contains the statement that, "The time of treatment will vary with the progress realized and with the degree of saturation aimed at." It is to be remembered that Burchenal distinctly disclaimed in his testimony that he had anything to do with the invention of the process covered by the Kayser patents and we thus have a situation where Kayser invented the process and developed the product to the point where it was applicable to use as a food product. He came to America with a sample which, as appears from the written record taken from the files of the complainant, had a melting point of only $39^{\circ}$ and developed other samples with melting points of but $42^{\circ}$ and $43^{\circ}$ in his March 5 , I 908 , experiments.

Moreover, it is to be remembered that Crossfield had em. ployed Kayser to experiment in hydrogenating oil, that the former had been in close communication with Normann, who had patented only four years before the process I have mentioned and that Crossfield had so strenuously objected to the use by Procter \& Gamble of the processes of Kayser that they were obliged to purchase their rights to them. It is also noteworthy that Kayser refused to testify in this case and that the witnesses as to the work of Kayser in America are officers or employees of the complainant. Under such circumstances the meagerness of the evidence which has been adduced to show that Burchenal had anything to do with the development of the lard-like food product which is the subject of the patent in suit, coupled with his admission that the entire process under which it was made was the work of Kayser, is most significant and makes it impossible to find that Burchenal invented anything. The defendant has been embarrassed in its defense by many difficulties and has been obliged to go into the enemy's camp to secure almost all its ammunition. In spite of this, it has been established that Kayser at the very beginning had developed not only a process but a product little differing from Crisco. Kayser remained with Procter \& Gamble until well into rgio, and did not leave America until about July of that year. While there is some general evidence of what Burchenal and others did, or directed, I can find no real proof that anyone but Kayser did anything of substantial moment. No step was taken by Burchenal that could possibly amount to invention.

Complainant urges that the experiments of Kayser and the patents of Normann and Kayser aimed at complete saturation and that neither realized the importance of a partially hydrogenized product. But the process under which their products were made involved in its progress partial hydrogenation, and Kayser's patent, No. I,004,035, distinctly stated that "The time of treatment will vary with the progress realized and with the degree of saturation aimed at." Kayser, as far as I can see, did everything that was done to develop Crisco, and if his work fell short of this, he achieved enough so that the final step was inevitable to one skilled in the art. Kayser's process was the complainant's process and his product involved a progressive reaction fitted for any purpose. The broad dis. covery as between him and Burchenal certainly belongs to him.

Furthermore, under any fair interpretation of the patent, there is no infringement. The file wrapper indicates that the examiner rejected the claims as originally filed, saying:

* * If the problem of simulating lard from cottonseed oil were presented to an oil chemist, an incomplete hydrogenization of the cottonseed oil would at once suggest itself to him as a solition of the problem. All the claims are accordingly rejected on the *** ground of lack of invention.

Thereafter new claims were rejected upon the Kavser patents for the reason that his process could be arrested at any time to produce an incompletely hydrogenized product. Then, and for the first time, Burchenal filed an amendment setting forth certain percentages of linolin, olein and stearin which his product should contain. It seems quite evident, therefore, that Claims I and 2 of his patent would, under such circumstances, if valid at all be limited to substantially the chemical composition described in the amended specification. Indeed, the specification closes with the statement that the inventor has produced a product which is high in olein, low in linolin and lesser saturated fats and with only enough stearin to make the product congeal at ordinary temperatures."

Under such circumstances it is impossible to treat the melting point as practically the determining factor, and if this is not done the defendants' product Kream Krisp does not infringe. After the examiner had held that an incomplete hydrogenation would suggest itself to any chemist seeking to simulate lard and rejected the claims on Kayser, the patentee, as I have shown amended by specifying a particular product and dwelling upon the advantages of a small percentage of linolin to avoid rancidity. If, therefore, the inventor contributed anything to the art it was this special chemical composition which his patent discloses. Claims I and 2 should consequently be construed in the light of the proceedings of Burchenal before the Patent Office and not given a scope which would monopolize an art in which Normann, Kayser and others had been the real pioneers.

Kream Krisp has a chemical composition extremely remote from that described in the specification of Burchenal. The following are the relative percentages: 


\begin{tabular}{|c|c|c|}
\hline PER CENT & BURCHENAL & $\mathrm{K}_{\mathrm{R} E A M} \mathrm{~K}_{\mathrm{RISP}}$ \\
\hline Saturated fats... & 20 to 25 & 28.0 \\
\hline Olein.... & 65 to 75 & 34.3 \\
\hline Linolin $\ldots \ldots \ldots \ldots \ldots \ldots \ldots \ldots$ & 5 to 10 & 37.7 \\
\hline
\end{tabular}

Thus it appears that Kream Krisp, instead of being low in linolin, is extremely high, and that instead of being high in olein as specified in the Burchenal patent, it has a percentage of olein which differs but little from that existing in refined cottonseed oil unhydrogenated. In fact, Kream Krisp seems to present many of the objections referred to in Burchenal's specification and to lack the very things upon which the latter based his right to receive a patent. Indeed, the composition is much closer to the lard compound Jewel made out of stearin and cottonseed oil than to Crisco.

The bill should be dismissed with costs because the patent is void for lack of invention and for the further reason that Claims $I$ and 2 , if properly construed, are not infringed by the defendant.

\section{THE AMERICAN COAL-TAR PRODUCTS INDUSTRY PRODUCTION TO BE ASCERTAINED BY THE UNITED STATES TARIFF COMMISSION}

The United States Tariff Commission is planning to ascertain the production within the United States during 19 I 7 of all substances treated in Title V of the Special Tariff Act of September 8, igr6. The substances there enumerated may be classed under the general name Coal-Tar Products and are divided into three groups.

Group I includes "all products that are found naturally in coal tar, whether produced or obtained from coal tar or other source" except phenol. These substances are admitted free of duty.

Group II includes the so-called Intermediates and are made dutiable at I $_{5}$ per cent plus $2^{1 / 2}$ cents per pound.

Group III includes "all colors, dyes, or stains, whether soluble or not in water, color acids, color bases, color lakes, photographic chemicals, medicinals, flavors, synthetic phenolic resins or explosives, not otherwise specially provided for in this title, when obtained, derived or manufactured, in whole or in part from any of the products provided for in Groups I and II." These articles are dutiable at 30 per cent plus 5 cents per pound with certain exceptions which are dutiable at 30 per cent.

Under the law the duties are made dependent on the growth of the industry within the United States. It is therefore the intention of the Commission to follow this growth from year to year in order to report the facts to Congress.

The Tariff Commission is planning to send to each manufacturer a questionnaire calling for information in regard to his production during 1917 of each separate commodity, as well as for certain other data. This information will be published in such a form that the operations of individual firms will not be disclosed. A preliminary questionnaire has recently been sent out, designed to aid in perfecting the mailing list. Any individual or firm engaged in the manufacture of any of these articles which did not receive a copy of the preliminary questionnaire is requested to write to the United States Tariff Commission, Washington, D. C., to insure being placed on the mailing list.
U. S. TARIFF CoMmisston
F. W. Taussig, Chairman

WASHINGION, November 5, 1917

\section{SAMPLING FATS AND OILS-CORRECTION}

In the "Tentative Standard Methods for the Sampling and Analysis of Commercial Fats and Oils other than those of the Coconut, Butter and Linseed Groups" as published in THis JourNAL, 9 ( 1917 ), IO66, the strength acid for acidifying under determination of TITER, page I068 (Ist column, 4th line above foot-notes), should read " 30 per cent" instead of " 50 per cent." November 17,1917

\section{CONCERNING THE MANUFACTURE OF PHTHALIC ACID AND PHTHALIC ANHYDRIDE}

The Department of Agriculture announced on June I6, 1917, that the Color Investigation Laboratory of the Bureau of Chemistry of this Department had perfected on a laboratory scale a new process for the mantfacture of phthalic acid and phthalic anhydride, and invited coöperation with the manufacturers for the purpose of testing this laboratory process upon a commercial scale. It was also stated in the announcement that the offer of assistance would not be held open by the Department for an indefinite period.

Arrangements have been made with several concerns to test this process on a commercial scale and the Color Investigation Laboratory is not in a position to receive or handle any additional offers of coöperation. The offer made on June 16,1917 , therefore, is withdrawn and no additional offers of coöperation can be considered.

DEPARTMENT OF AGRICULTURE

WASHINGTON, November 1, 1917

\section{F. Houston, Secretary}

\section{CHICAGO CHEMICAL EXPOSITION PLANS ABANDONED}

After serious consideration and correspondence with all exhibitors, the managers of the Chemical Exposition have decided to abandon plans to hold a Chemical Exposition in Chicago in the Spring. This action was taken because of insufficient support secured to make a large and representative exposition, all the exhibitors wishing to confine their efforts toward making the Fourth National Exposition of Chemical Industries in New York, week of Seplember 23, 1918, the greatest event in the history of American Chemical Industry, it being their intention to show there the many advances they are making as a result of their researches.

\section{NITRIC ACID SOPHISTICATION-CORRECTION}

The following corrections should be made in my article printed in ThIS JoURNaL, 9 (I9I7), $77 \mathrm{r}$ :

Page 775, 2nd col., line 44,

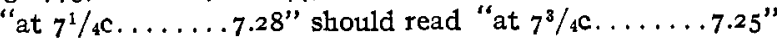

P. 776 , ist col., line 18 ,

"I27 lbs.....\$10.16" should read "I 27.77 lbs....\$10.22"

line I9, "I.82" should read "\$1.88"

line $2 \mathrm{I}$, "I.5I" should read " $\$ \mathrm{I} .54$ "

line 23, "0.5 r" should read "\$0.53"

October 29, 1917

JAMES R. WITHROW

\section{THE DETERMINATION OF SULFUR DIOXIDE- CORRECTION}

The following corrections should be made in my article printed in ThIS JouRNaL, 9 (I917), 949:

Page 949, 2nd col., line 34, omit "Both Dymond and Hughes and the Selby Smelter Commission used sodium sulfite for their standard."

Page 950, Ist col., first line under heading APPARATus should read "One extra heavy 24-liter, or larger, bottle such as a carboy, carefully housed to avoid serious trouble from collapse and, etc."

Page 950, first line under heading METHOD OF PROCEDURE should read "Large sample bottle is evacuated to about 380 $\mathrm{mm}$. and the pressure, etc."

November 8, 1917

JAMES R. WITHROW 